\title{
Hubungan Keseimbangan Dinamis dengan Activity of Daily Living pada Lansia Muda
}

\author{
${ }^{1}$ Istimrorul Najibatil Fikriyah, ${ }^{2}$ Adnan Faris Naufal, ${ }^{3}$ Wijianto \\ Program Studi Fisioterapi, Fakultas Ilm Kesehatan, Universitas Muhammadiyah Surakarta \\ Jl. A. Yani Tromol Pos I Pabelan Kartasura Telp. (0271) 717417 Fax. (0271) 715448 Surakarta 57162
}

Email : infikriyah@gmail.com

Tanggal Submisi: 29 Januari 2020; Tanggal Penerimaan: 21 Juni 2021

\begin{abstract}
ABSTRAK
Latar Belakang: Lanjut usia sering kali mengalami permsalah yag diakibatkan penuruan fusngsi tubuh sehingga dapat mempengaruhi kondisi tubuhnya. Gangguan keseimbangan merupakan penyebab utama cedera serta keterbatasan saat melakukan Activity of Daily Living pada lansia, Masalah ADL dipengaruhi oleh beberapa penyakit dan perubahan usia yang akan menyebabkan keterbatasan fungsional sehingga dapat mempengaruhi kinerja aktual. Penilitian ini bertujuan untuk melihat apakah ada hubungan antara keseimbangan dinamis dengan Activity of Daily Living pada lansia Muda. Metode Penelitian: Jenis Penelitian ini menggunakan observational dengan pendekatan cross sectional. Penelitian dilakukan di Komunitas Lansia Abadi Gonilan. Sampel peneltian berjumlah 58 responden pada lansia muda berusia 6069 tahun. Teknik Sampling menggunakan Purposive Sampling. Tes keseimbangan menggunakan Timed Up and Go Test dan Questionnaire ADL menggunakan The Lawton Instrumental Activity of Daily Living. Hasil: Teknik analisis data uji normalitas yaitu dengan menggunakan Kolmogorov-Smirnov dan didapatkan hasil tidak normal dengan nilai hasil $\mathrm{p}<0.005$. Uji hubungan menggunakan uji spearman rank dan dipatkan hasil ada hubungan antara Keseimbangan Dinamis dengan Activity of Daily Living Pada Lansia Muda di Komunitas Lansia Abadi Gonilan dengan nilai $p=0.000$ dan nilai $r=-0,715$. Kesimpulan: Hasil penelitian menunjukkan bahwa ada hubungan kuat antara keseimbangan dinamis dengan Activity of Daily Living pada lansia muda.
\end{abstract}

Kata Kunci : Activity of Daily Living, IADL, Keseimbangan Dinamis, Lansia Muda, TUGT

\begin{abstract}
Background: In old age often affected by physical disorders caused by a decrease in physiological abilities that can affect the condition of the body. Impaired balance is a major cause of injury and limitations when doing Activity of Daily Living in the elderly, ADL problems are influenced by several diseases and changes in age which will cause functional limitations so that it can affect actual performance. This research aims to see whether there is a relationship between dynamic balance and Activity of Daily Living in the elderly. Methods: This type of research uses observational with cross sectional approach. The study was conducted in the Seniors Abadi Community Gonilan. The research sample was 58 respondents in young elderly aged 60-69 years. Sampling technique using Purposive Sampling. The balance test uses the Timed Up and Go Test and the ADL Questionnaire uses The Lawton Instrumental Activity of Daily Living. Results: The technique of analyzing normality test uses Kolmogorov-Smirnov and the results are abnormal with the results of $p<0.005$. The relationship test uses the Spearman rank test and the result is a correlation between the Dynamic Balance and the Activity of Daily Living in the Young Elderly in the Elderly Community of Gonilan with a value of $p=0,000$ and a value of $r=-0,715$. Conclusion: The results showed that there was a strong relationship between dynamic balance and Activity of Daily Living in young elderly.
\end{abstract}


Keywords: Activity of Daily Living,IADL, Dynamic Balance, Young Elderly, TUGT

\section{PENDAHULUAN}

Indonesia merupakan negara berkembang yang setiap tahunnya mempunyai jumlah lanjut usia yang semakin terus bertambah (Azianah, et al., 2017). Berdasarkan peraturan dari pemerintah nomor 43 tahun 2004, Lanjut usia atau Lansia merupakan seseorang yang sudah memasuki usia enam puluh tahun ke atas (Kementrian Kesehatan RI, 2017). Lanjut usia atau Lansia seringkali mengalami penurunan kemampuan fungsional, partisipasi dalam kegiatan fisik maupun sosial, dan jatuh merupakan ancaman besar bagi lansia dalam mengalami risiko tersebut (Phelan, et al., 2015).

Penilaian status fungsional sangat penting ketika merawat lansia. Perubahan yang normal seperti penuaan, penyakit akut maupun kronis, dapat menurunkan kemampuan untuk melakukan tugas-tugas yang diperlukan untuk hidup mandiri di masyarakat (Robin Coyne, 2019). Fungsi ADL merupakan hasil interaksi yang kompleks dari faktor fisiologis, kognitif, dan juga psikologis. Masalah ADL dipengaruhi oleh beberapa penyakit dan perubahan usia yang akan menyebabkan keterbatasan fungsional sehingga dapat mempengaruhi kinerja aktual (Bravell, et al., 2011).

Gangguan keseimbangan adalah penyebab utama cedera serta keterbatasan aktivitas pada lansia, dan efek buruk yang terkait dengan masalah tersebut adalah jatuh yang dapat menyebabkan masalah pada individu, sosial dan ekonomi yang signifikan. (Barry, et al., 2014).

Penelitian menunjukkan bahwa wanita memiliki gangguan keseimbangan lebih tinggi daripada lansia laki-laki yang dapat menyebabkan cedera nonfatal. Namun, dalam penelitian lain menyebutkan bahwa lansia lakilaki saat mengalami cedera dapat menyebabkan risiko lebih fatal daripada lansia perempuan
(Skelton, et al., 2017). Sedangkan berdasarkan hasil penelitian lain menunjukkan bahwa dari 424.000 lansia di Asia Tenggara 80\% mengalami risiko jatuh fatal sehingga menyebabkan kematian dan jatuh pada perempuan lebih tinggi (29.1\%) daripada laki-laki(23,5\%) (Nurmalasari, et al., 2018).

Pada usia lanjut seringkali terkena gangguan fisik yang disebabkan karena penurunan pada kemampuan fisiologisnya sehingga dapat mempengaruhi kondisi tubuhnya (Ibrahim, et al., 2017). Pada usia lanjut risiko jatuh rata-rata terjadi pada lansia berusia 65 tahun dan meningkat saat berusia 80 tahun (kang, et al., 2017). Dari penjabaran di atas, maka peneliti tertarik untuk dapat melakukan penelitian tentang permasalahan tersebut dengan tujuan ingin mengetahui apakah ada Hubungan Keseimbangan Dinamis dengan Activity of Daily Living pada Lansia Muda.

\section{METODE PENELITIAN}

Permasalahan pada judul ini yaitu akan membahas tentang keseimbangan dinamis dengan Activity of Daily Living pada lansia muda. Maka jenis penelitian yang dilakukan yaitu observational dengan jenis penelitian cross sectional agar mengetahui hubungan keseimbangan dinamis dengan Activity of Daily Living pada lansia, kegiatan yang dilakukan dalam pengumpulan data hanya dilaksanakan dari satu responden dalam satu waktu saja, Lokasi penelitian di lakukan di Komunitas Lansia Abadi Gonilan. Penelitian tersebut dilaksanakan pada tanggal 14 dan 17 Desember 2019. Sampel penelitian dipilih dengan metode purposive sampling yang sudah sesuai dengan kriteria inklusi yang telah ditentukan. Sampel penelitian berjumlah 58 orang diambil dari penduduk yang berusia 60-69 tahun yang terdaftar sebagai penduduk di Komunitas Lansia Abadi 
Fikriyah I.N., Naufal A.F. \& Wijianto

Fisiomu.2021 Vol 2(1): 59-64

DOI : 10.23917/fisiomu.v2i2.10060

Gonilan. Tes keseimbangan menggunakan pemeriksaan Timed Up and Go Test yang dibagi menjadi empat kategori yaitu: 1) kurang dari 10 detik memiliki arti mandiri penuh (normal); 2) 10-19 detik menujukkan risiko jatuh ringan; 3) 20-29 detik memiliki arti risiko jatuh sedang; dan 4) lebih dari 30 detik menujukkan risiko jatuh tinggi (Nurmalasari, et al., 2018). Dalam penelitian ini, peneliti menggunakan Questionnaire The Lawton Instrumental Activities of Daily Living (IADL) yang memiliki 8 item dengan skor 0-8 dan kategori bergantung-mandiri (Lawton \& Brody, 2019).

Dalam penelitian ini sudah mendapatkan persetujuan dan dinyatakan lolos etik dari Fakultas Kedokteran bagian Komisi Etik Penelitian Kesehatan (KEPK) Universitas Muhammadiyah Surakarta dengan nomor 2607/B.1/KEPK-FKUMS/XI/2019.

\section{HASIL}

Responden pada penelitian ini diambil hanya pada lansia muda berjenis kelamin perempuan dengan batasan usia 60-69 tahun.

Tabel 1 Karakteristik Responden Berdasarkan Umur

\begin{tabular}{ccc}
\hline Umur (tahun) & Frekuensi & Presentase \\
\hline 60 & 3 & $5 \%$ \\
\hline 61 & 5 & $9 \%$ \\
\hline 62 & 9 & $16 \%$ \\
\hline 63 & 2 & $3 \%$ \\
\hline 64 & 8 & $14 \%$ \\
\hline 65 & 8 & $14 \%$ \\
\hline 66 & 10 & $17 \%$ \\
\hline 67 & 5 & $9 \%$ \\
\hline 68 & 1 & $2 \%$ \\
\hline 69 & 7 & $12 \%$ \\
\hline Total & $\mathbf{5 8}$ & $\mathbf{1 0 0 \%}$ \\
\hline Mean & $\mathbf{6 4 . 5}$ & \\
\hline Minimum & $\mathbf{6 0}$ & \\
\hline Maksimum & $\mathbf{6 9}$ & \\
\hline Std. Deviation & $\mathbf{3 . 0 2 8}$ & \\
\hline
\end{tabular}

Berdasarkan Tabel 1 menyebutkan tentang nilai karakteristik responden berdasarkan umur, responden berusia 60-69 tahun adalah sebanyak 58 orang dengan usia rata-rata 64.5 tahun, angka usia terendah yaitu 60 tahun dan untuk usia tertinggi yaitu 69 tahun.

Penelitian ini dilakukan uji normalitas data responden yang telah dilakukan test keseimbangan menggunakan Timed $U p$ and go Test dan questionnaire Instrumental Activity of Daily Living dengan The Lawton. Hasil uji normalitas ditampilkan pada Tabel 2.

Tabel 2 Hasil Analisis Uji Normalitas Keseimbangan Dinamis dengan Activity of Daily Living

\begin{tabular}{cccccc}
\hline Pemeriksaan & Min & Max & Mean & Sig & Hasil \\
\hline TUGT & 6.85 & 13.63 & 10.1595 & 0.035 & Tidak Normal \\
\hline IADL & 3 & 8 & 6.29 & 0.000 & Tidak Normal \\
\hline \multicolumn{2}{c}{ Berdasarkan } & dari analisis & hasil uji
\end{tabular}
normalitas diatas didapatkan nilai $p$-value pada TUGT dan IADL menunjukkan nilai $\mathrm{p}<0.005$, sehingga dapat dikatakan bahwa data uji normalitas tersebut adalah berdistribusi tidak normal.

Pada peneltian ini, peneliti melakukan pemeriksaan keseimbangan dinamis dengan meggunakan Timed Up and Go Test yang memiliki 4 kategori nilai yaitu normal atau keseimbangan penuh, risiko jatuh ringan, risiko jatuh sedang dan risiko jatuh berat. Hasil tingkat skor dijelaskan pada diagram berikut:

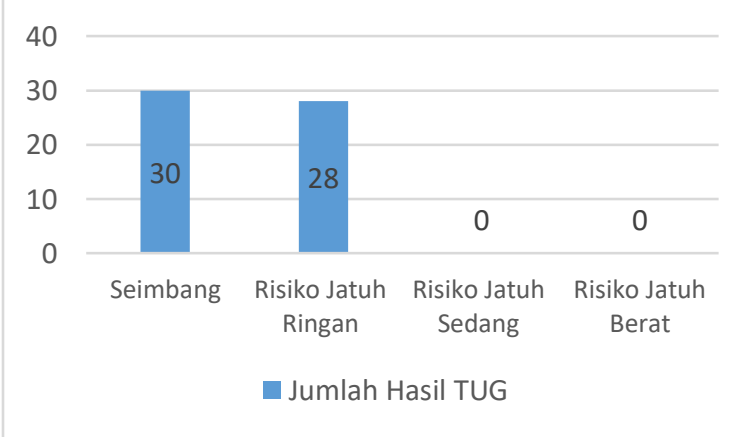

Gambar 1 Diagram Timed Up and Go Test

Berdasarkan gambar diagram 1 menunjukkan bahwa dari 58 responden, Lansia dengan keseimbangan normal sebanyak 30 responden dan 
Fikriyah I.N., Naufal A.F. \& Wijianto

Fisiomu.2021 Vol 2(1): 59-64

DOI : 10.23917/fisiomu.v2i2.10060

jatuh ringan sebanyak 28 responden, sedangan untuk tingkat jatuh sedang dan jatuh berat nilai nol.

Pada peneltian ini, peneliti melakukan Questionnaire Activity of daily Living dengan meggunakan The Lawton Instrumental Activity of Daily Living yang memiliki 2 kategori nilai yaitu Mandiri dan Bergantung. Hasil tingkat skor dijelaskan pada diagram berikut:

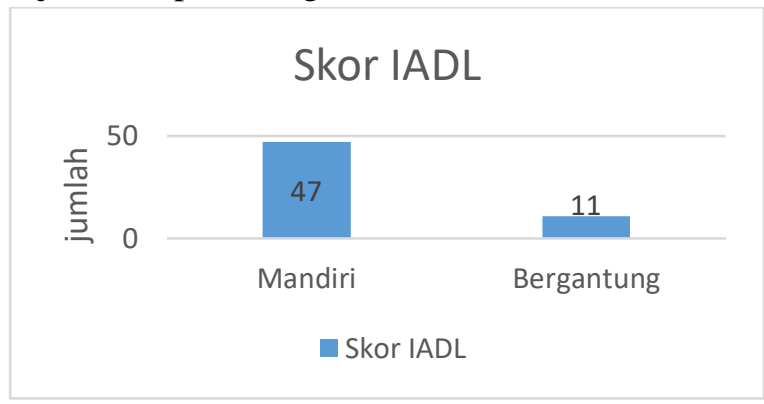

Gambar 2 Diagram Activity of Daily Living

Berdasarkan gambar diagram 2 menunjukkan bahwa hasil Activity of Daily Living dari total 58 responden tingkat mandiri lebih tinggi sebanyak 47 Responden sedangkan tingkat bergantung sebanyak 11 Responden.

Untuk menguji hubungan Keseimbangan

Dinamis dengan Activity of Daily Living menggunakan uji Spearman Rank karena hasil dari uji normalitas menunjukkan data berdistribusi tidak normal.

Tabel 3 Hasil Analisis Uji Hubungan Keseimbangan Dinamis dengan Activity of Daily Living

\begin{tabular}{ccccc}
\hline Pemeriksaan & $\mathrm{N}$ & Mean & Sig & Correlation Coefficient \\
\hline TUGT & 58 & 10.1595 & 0.000 & -0.715 \\
\hline IADL & 58 & 6.29 & 0.000 & -0.715
\end{tabular}

Berdasarkan dari hasil perhitungan analisis uji hubungan dengan menggunakan Spearman Rank didapatkan nilai Correlation Coefficient pada TUGT dan IADL menunjukkan nilai -0.715 sehingga dari nilai tersebut dapat disimpulkan bahwa ada hubungan Keseimbangan Dinamis dengan Activity of Daily Living pada lansia muda.

\section{PEMBAHASAN}

Berdasarkan penelitian sebelumnya menjelaskan bahwa penggunaan Time $U p \&$ \&o Test secara signifikan lebih baik pada lansia yang lebih muda yaitu berusia 60-69 tahun, dibandingkan dengan yang lebih tua yaitu berusia 70-79 tahun dan kelompok tertua berusia lebih dari 80 tahun. Selain itu, Subyek yang lebih tua dari 80 tahun memiliki skor ADL secara signifikan lebih buruk (Zasadzka, et al., 2015) dan pemeriksaan dengan menggunakan Intrumental Activity of Daily Living, Time Up \& Go Test dan test tambahan termasuk analisis yang valid untuk mengukur kecepatan gaya berjalan, aktivitas fisik, kelelahan, keseimbangan, dan masalah pada Activity of Daily Living (Gobbens \& Assen, 2014).

TUG adalah tes dasar mobilitas fungsional yang memiliki kemampuan tinggi untuk mengukur keseimbangan pada lansia. Tes ini mengukur kecepatan yang meliputi berdiri, berjalan, berbalik dan duduk. Dalam penelitian sebelumnya menunjukkan bahwa TUG tidak dapat digunakan sebagai tes untuk risiko penurunan populasi lansia rawat jalan namun ada hubungan statistik antara tes TUG dengan riwayat jatuh lansia (Kim, et al., 2017).

Pada penelian tentang TUGT ada pendapat lain yang mengatakan bahwa TUGT mampu menilai fungsi ekstremitas, mobilitas dan risiko jatuh. Hal ini tidak hanya terkait dengan fungsi motorik, tetapi juga dengan fungsi kognitif. Penilaian TUGT memiliki hubungan dengan riwayat jatuh dimasa lalu, tapi kemampuan untuk memprediksi jatuh dimasa depan terbatas sehingga dalam melakukan penilaian risiko jatuh, selain dengan menggunakan TUGT dapat menggunakan kombinasi dengan tes lain (Hager, et al., 2019).

\section{KESIMPULAN DAN SARAN}


Kesimpulan dari penelitian dengan judul "Hubungan Keseimbangan Dinamis dengan Activity of Daily Living pada Lansia Muda" yang dilakukan satu waktu pada komunitas Lansia Abadi Gonilan RW 01 dan RW 07 dapat diambil kesimpulan bahwa ada hubungan kuat dari keseimbangan dinamis dengan Activity of Daily Living pada Lansia Muda yang disebutkan dari hasil nilai $\mathrm{p}=0.000$ dan nilai $\mathrm{r}=-0,715$. Berdasarkan kesimpulan tersebut maka peneliti memberikan saran untuk peneliti yang ingin menggunakan judul penelitian sama agar dapat menggunakan alat ukur yang tidak bersifat subjektif .

\section{DAFTAR PUSTAKA}

Azianah, I., Singh, D. K. A., Suzana, S. \& Omar, M. A., 2017. Timed Up and Go' test: Age, gender and cognitive impairment stratified normative values of older adults. plosone, Volume 10, p. 12.

Barry, E. et al., 2014. Is the Timed Up and Go test a useful predictor of risk of falls in community dwelling older adults: a systematic review and meta- analysis. BMC Geriatrics, pp. 1-14.

Bravell, M. E., Zarit, S. H. \& Johansson, B., 2011. Self-reported activities of daily living and performance-based functional ability: a study of congruence among the oldest old. Springer Verlag, Issue 8, p. 2.

Gobbens, R. J. J. \& Assen, M. A. L. M. v., 2014. The Prediction of ADL and IADL Disability Using Six Physical. Current Gerontology and Geriatrics, 24 March, p. 1.

Hager, A. G. M. et al., 2019. Effects of three home-based exercise programmes regarding falls, quality of life and exercise-adherence in older adults at risk of falling: protocol for a randomized controlled trial. BMC GERIATRICS, Issue 19, p. 6.

Ibrahim, A., Singh, D. K. A., Shahar, S. \& Omar, M. A., 2017. Journal of Multidisciplinary Healthcare, p. 410.

kang, L. et al., 2017. Timed Up and Go Test can predict recurrent falls: a longitudinal study of the community-dwelling elderly in China. Clinical Interventions in Aging, Issue 12, p. 2009.

Kim, J. C. et al., 2017. The Association Between Fall History and Physical Performance Tests in the CommunityDwelling Elderly: A Cross-Sectional Analysis. Annals of Rehabilitation Medicine, 2(41), p. 6.

Lawton \& Brody, 2019. The Lawton instrumental Activities of Daily Living Scale. In: S. A. Greenberg, ed. Try This. New York: Coyne, Robin; Kluwer, Wolters, pp. 179-186.

Nurmalasari, M., Widajanti, N. \& Dharmanta, R. S., 2018. Correlation between history of fall and timed up and go test in geriatric, Indonesia: Fakltas Kedokteran Universitas Airlangga Surabaya.

Phelan, E. A., Mahoney, J. E., Voit, J. C. \& Stevens, J. A., 2015. Assessment and Management of Fall Risk in Primary Care Settings. HHS Public Access, pp. 281293.

RI, K. K., 2017. Analisis Lansia, Indonesia: Kementrian Kesehatan RI.

Robin Coyne, M. R. (., 2019. The Lawton Instrumental Activities of Daily Living 
Fikriyah I.N., Naufal A.F. \& Wijianto Fisiomu.2021 Vol 2(1): 59-64 DOI : 10.23917/fisiomu.v2i2.10060

(IADL) Scale. Best Practices in Nursing, Issue 23.

Skelton, M. S. D. A. et al., 2017. Gender perspectives on views and preferences of older people on exercise to preferences of older people on exercise to review. BMC GERIATRICS, p. 2.
Zasadzka, E., Borowicz, A. M., Roszak, M. \& Pawlaczyk, M., 2015. Assessment of the risk of falling with the use of timed up and go test in the elderly with lower extremity osteoarthritis. Clinical Interventions in Aging, Issue 11, p. 1289. 